\title{
Maternal Factors Associated with Smoking and Inappropriate Weight Gain During Pregnancy
}

\author{
Richard May*
}

Biology Department, Southern Oregon University, 1250 Siskiyou Blvd., Ashland, OR 97520, USA

\begin{abstract}
This study was designed to identify maternal characteristics associated with smoking during pregnancy and inappropriate gestational weight gain. Data were collected retrospectively from records of 252 women enrolled in the Siouxland WIC (Women, Infants, and Children) program in Sioux City, Iowa. Twenty-three percent of women reported smoking during pregnancy. Forty-four percent of women gained more weight than recommended during pregnancy and 21 percent gained less than recommended.

Maternal demographic characteristics were tested as predictors of inappropriate gestational weight gain and smoking using logistic regression analysis. Adjusted odds ratios indicated that smoking was predicted by lower income, being unmarried, white (non-Hispanic) ethnicity, and living with another smoker. Excess pregnancy weight gain was predicted by white ethnicity, primigravid status, and being overweight (but not obese) before pregnancy. Risk of smoking and excess weight gain was highest among women with multiple identified risk factors. Smoking and excess gestational weight gain are both common in this low-income population but have different patterns of demographic risk.
\end{abstract}

\section{INTRODUCTION}

Smoking during pregnancy poses significant health risks for both mother and fetus [1,2]. Smoking clearly inhibits fetal growth, increasing the risk of low birthweight $[3,4]$ and may indirectly affect fetal development by impairing maternal weight gain [2]. Smoking during gestation may also pose longer-term risks for child health, independent of fetal growth restriction [5]. Although prevalence is decreasing in the population as a whole, many women continue to smoke during pregnancy [6]. Recent studies have linked smoking during pregnancy to demographic factors such as ethnicity, maternal age, income, and education [7-9].

Inappropriate gestational weight gain may also pose health risks for mother and fetus. Nationally, most women gain more weight than recommended during pregnancy [10], a trend that seems to be increasing [11]. Among non-obese women, increased maternal weight gain tends to increase the risk of large-for-gestational age infants [12, 13]. Excess weight gain may also increase risk of maternal obesity after pregnancy [14]. This in turn presents a risk for subsequent pregnancies as overweight women face higher risk of pregnancy and birth complications [15]. Gestational weight gain outside the recommended ranges has been linked to a variety of maternal characteristics, including ethnicity, body size, and pregnancy history [10].

Although a number of studies have focused on effects of gestational smoking and weight gain on maternal health and fetal development [16-18], fewer studies have identified maternal characteristics associated with these pregnancy risk

*Address correspondence to this author at the Biology Department, Southern Oregon University, 1250 Siskiyou Blvd., Ashland, OR 97520, USA; Tel: 541-552-6867; Fax: 541-552-6415; E-mail: mayr@sou.edu factors $[19,20]$. Given the potential impact of these risk factors, additional study is needed comparing maternal predictors of both smoking and inappropriate gestational weight gain in the same population. Such studies are critical for identification of high risk sub-groups in local populations. More information is also needed regarding the co-occurrence of risk factors and the additive effect on risk of smoking and inappropriate gestational weight gain. This study addresses these questions for women from a low-income, ethnically diverse population.

\section{MATERIALS AND METHODOLOGY}

Data were collected retrospectively from maternal records for all women $(n=309)$ enrolled in the Siouxland WIC (Women, Infants, and Children) program as of February, 2001. WIC is a federal program that provides supplemental foods, nutrition education, and other services to primarily low-income families [21]. Pregnant mothers and children under five years of age are eligible for enrollment in the program. The Siouxland WIC agency in Sioux City serves eligible families in Woodbury County which is located in northwest Iowa. The entire WIC population of Woodbury County is approximately 30 percent Hispanic [22]. Data were collected for the most recent singleton live birth with a gestation length of at least 28 weeks. Based on interviews with WIC staff and dietitians, all women completed a Prenatal Health History form and a Breastfeeding / Postpartum form. Prepregnancy weight, height, pregnancy weight gain, and smoking were reported by the mothers. Pre-pregnancy weight and height were used to calculate body mass index (BMI).

Reported number of cigarettes smoked per day during the last 3 months of pregnancy was recorded on the Breastfeeding / Postpartum form and coded as never smoked or smoked during pregnancy. Presence of another smoker in the home 
was also coded dichotomously. Weight gain during pregnancy was coded as low, normal, or high based on recommendations that take pre-pregnancy BMI into account (Institute of Medicine 1990). Gestational weight gain for women with a low BMI was recorded as either high $(>18 \mathrm{~kg})$ or low $(<12.5 \mathrm{~kg})$. For women within the normal BMI range, weight gain was recorded as high $(>16 \mathrm{~kg})$ or low $(<11.5$ $\mathrm{kg}$ ). For overweight or obese women, weight gain was recorded as high $(>11.5 \mathrm{~kg})$ or low $(<7 \mathrm{~kg})$.

Maternal demographic predictor variables were dummy coded to facilitate estimation of odds ratios. Reported monthly household income was verified by WIC staff based on required documentation. Household income was coded as lower or higher based on the group median. Marital status was coded as married or not married / separated. Maternal age was coded as under 20 or 20 and older. Since the majority of the sample was white $(57 \%)$ or Hispanic $(32 \%)$, maternal ethnicity was coded as white or non-white. Maternal education was coded as at least 12 years or less than 12 years. Gravidity was coded as previously pregnant or primigravid. Gestational week of the first prenatal care visit was coded according to the group median. Based on BMI, mothers were classified as underweight $(\mathrm{BMI} \leq 19.8)$, not overweight $(\mathrm{BMI}>19.8$ and $\leq 26.0)$, overweight $(\mathrm{BMI}>26.0$ and $\leq 29.0$ ), or obese (BMI > 29.0), [23].

Demographic characteristics were first tested as individual predictors of smoking and inappropriate gestational weight gain using simple logistic regression. Multiple logistic regression models were also constructed to predict risk of smoking and weight gain status with all maternal characteristics as predictor variables. Advantages of this approach include estimation of independent effects of predictor variables and calculation of odds ratios adjusted for all other predictor variables. For all logistic models, maternal weight gain was dummy coded as excess weight gain or low weight gain with normal weight gain as the reference category. Pre-pregnancy BMI was dummy coded as underweight, overweight, or obese with normal BMI as the reference category. Pregnancy weight gain was included in the model predicting smoking and smoking was included in the model predicting pregnancy weight gain. All statistical analyses were performed using SYSTAT 10.2.

Effects of multiple maternal risk factors identified by multiple logistic regression analysis were also analyzed. The number of identified risk factors for smoking ( $0-4$ possible) and for excess weight gain ( $0-3$ possible) was calculated for each subject. Risk of smoking and excess gestational weight gain associated with having 2 or more of these risk factors was calculated. It was necessary to collapse risk categories due to the presence of empty cells for certain categories.

\section{RESULTS}

Data were collected for 309 women enrolled in the program. One case that was an extreme outlier in terms of reported pregnancy weight loss and another for whom race was not recorded were excluded. Two-hundred fifty-two women had complete data for all study variables. Forty-four percent of mothers had less than a high school education and 58 percent were unmarried (Table 1). Mothers ranged in age from 15 to 43 years and 21 percent were under 20 years old. Fifty-seven percent were white (non-Hispanic) and 74 per- cent of the non-white group was Hispanic. Twenty-eight percent of mothers were primigravid and the average first prenatal visit was 10.1 weeks. Based on BMI, 47 percent were overweight or obese before pregnancy. Based on prepregnancy BMI, 44 percent of women in the sample gained more weight than recommended during pregnancy and 21 percent gained less weight than recommended. Twenty-three percent of mothers reported smoking during pregnancy. Thirty-two percent of women reported living with another smoker in the home.

Certain individual maternal characteristics were significant predictors of smoking and inappropriate weight gain. Table 2 presents risk factors for smoking or inappropriate gestational weight gain. The percentage that smoked or that gained inappropriate pregnancy weight is listed for each level of the risk factor in addition to the unadjusted odds ratio. Smoking was predicted by lower income $(\mathrm{OR}=3.09$; $\mathrm{CI}=1.64-5.82)$, being unmarried/separated $(\mathrm{OR}=3.53$; $\mathrm{CI}=1.76-7.07)$, white (non-Hispanic) ethnicity $(\mathrm{OR}=5.67$; $\mathrm{CI}=2.64-12.19)$, and living with another smoker $(\mathrm{OR}=6.01$; $\mathrm{CI}=3.19-11.30$ ). Smoking was inversely predicted by lower education $(\mathrm{OR}=.44 ; \mathrm{CI}=0.24-0.83)$. That is, women with higher education faced higher risk of smoking during pregnancy $(\mathrm{OR}=2.72)$.

Excess weight gain during pregnancy was predicted by being unmarried/separated $(\mathrm{OR}=1.86 ; \mathrm{CI}=1.11-3.12)$, white (non-Hispanic) ethnicity ( $\mathrm{OR}=2.50 ; \mathrm{CI}=1.49-4.21)$, being less than 20 years old $(\mathrm{OR}=2.32$; $\mathrm{CI}=1.25-4.30)$, primigravid status $(\mathrm{OR}=2.55$; $\mathrm{CI}=1.45-4.48)$, being overweight before pregnancy $(\mathrm{OR}=6.40 ; \mathrm{CI}=2.73-15.02)$ and living with another smoker $(\mathrm{OR}=1.85 ; \mathrm{CI}=1.08-3.15)$. Low weight gain during pregnancy was inversely predicted by pre-pregnancy overweight $(\mathrm{OR}=.12 ; \mathrm{CI}=0.03-0.52)$ and obesity $(\mathrm{OR}=.44$; $\mathrm{CI}=0.22-0.90)$. That is, normal or underweight women faced higher risk of gaining less weight than recommended. The relationship between high weight gain and smoking was nearly significant $(\mathrm{OR}=1.79 ; \mathrm{CI}=0.99-3.24 ; \mathrm{p}=.05)$.

Table 3 presents results of the multiple logistic regression analyses. After adjusting for all other risk factors in the model, smoking during pregnancy was predicted by lower income $\quad(\mathrm{OR}=2.54 ; \quad \mathrm{CI}=1.17-5.53)$, being unmarried $(\mathrm{OR}=3.05 ; \mathrm{CI}=1.28-7.26)$, white (non-Hispanic) ethnicity $(\mathrm{OR}=4.64 ; \mathrm{CI}=1.70-12.66)$, and living with another smoker $(\mathrm{OR}=5.63 ; \mathrm{CI}=2.65-11.96)$. Excess pregnancy weight gain was predicted by white (non-Hispanic) ethnicity $(\mathrm{OR}=2.80$; $\mathrm{CI}=1.29-6.05)$, primigravid status $(\mathrm{OR}=2.42 ; \mathrm{CI}=1.11-5.33)$, and being overweight before pregnancy $(\mathrm{OR}=6.29 ; \mathrm{CI}=2.21$ 17.89). Being underweight or obese before pregnancy were not significant predictors of excess weight gain. Risk of low pregnancy weight gain was significantly lower among women that were obese before pregnancy $(\mathrm{OR}=0.41$; $\mathrm{CI}=0.18-0.96)$. Gestational age and household size were not significant predictors when included in either model.

Multiple logistic regression identified 4 significant risk factors for smoking and 3 significant risk factors for excess weight gain. Ninety-six women (38 percent) had 0 or 1 of the significant risk factors for smoking and 156 (62 percent) had 2-4 of these risk factors. Women in the higher risk group were 9 times as likely to smoke compared to those in the lower risk group $(\mathrm{OR}=9.34,95 \% \mathrm{CI}=3.59-24.44)$. Onehundred ninety six women (78 percent) had 0 or 1 of the 
Table 1. Demographic and Biological Characteristics of Mothers $(n=252)$

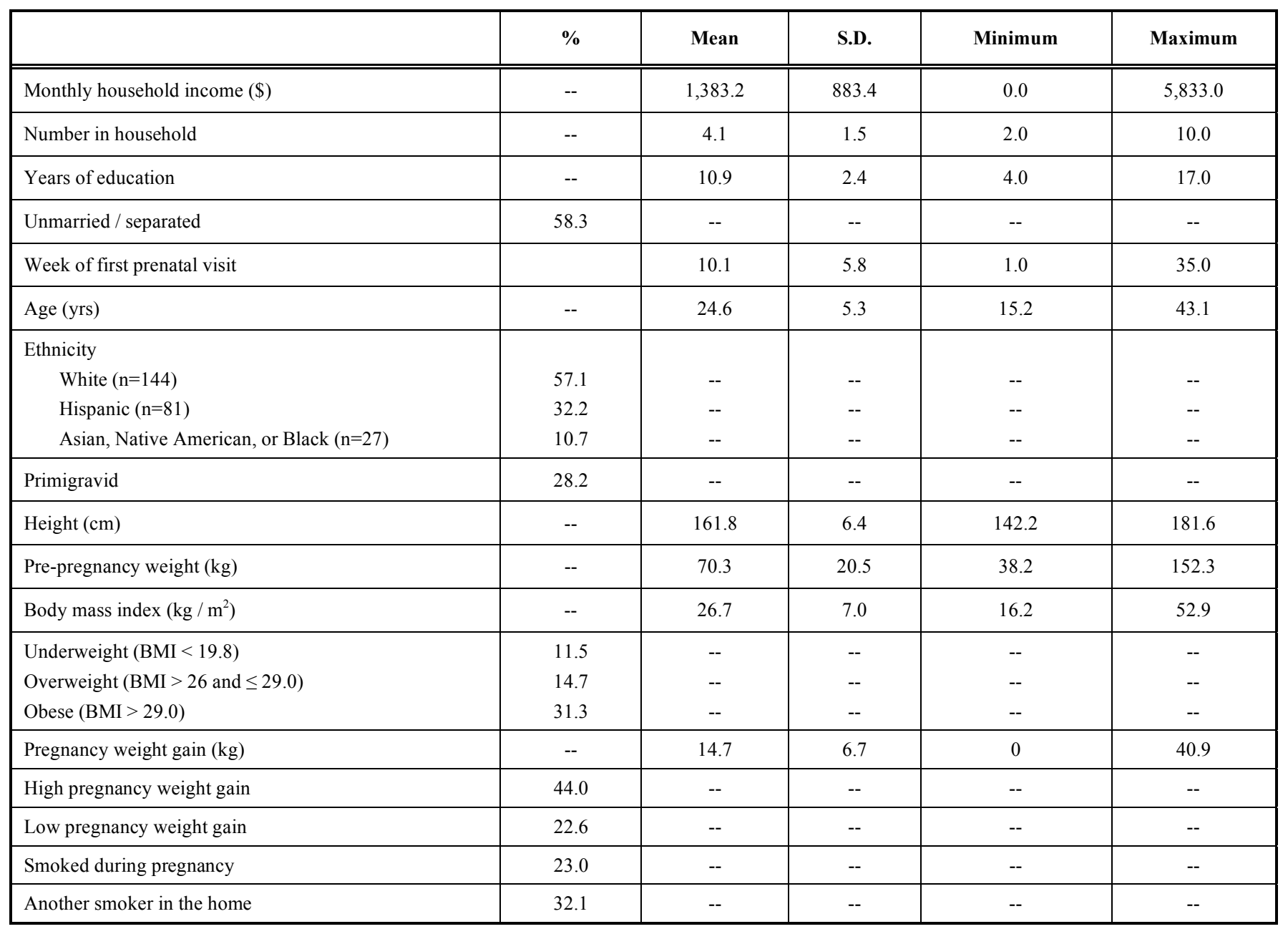

identified risk factors for excess weight gain while 56 (22 percent) had 2-3 of these risk factors. Women in the higher risk group were 8 times as likely to gain excess weight during pregnancy $(\mathrm{OR}=8.06,95 \% \mathrm{CI}=3.91-16.60)$.

\section{DISCUSSION}

A previous study based on this sample of WIC participants revealed significant effects of smoking and inappropriate weight gain on birthweight [24]. The present study extends this research to identify maternal characteristics associated with these risk factors. Although other studies have tested predictors of either smoking or weight gain, this study represents an important contribution by comparing predictors of both in a single sample. Unadjusted odds ratios revealed higher risk of smoking among women that were lower income, more educated, unmarried, white (non-Hispanic), or lived with another smoker. However, after adjusting for other risk factors, only income, marital status, race, and presence of another smoker remained significant. To clarify this difference, education level was tested as a predictor of smoking adjusting for other individual risk factors. This procedure suggested that the effect of education level was confounded by race / ethnicity. That is, smoking was much more common among white (non-Hispanic) mothers and they were more highly educated. Previous studies have reported increased risk of smoking for white (non-Hispanic) mothers
$[7,20,25]$ relative to other minority groups. Hispanic mothers in particular tend to report lower prevalence of gestational smoking $[8,26]$. In the current sample, prevalence of reported smoking among Hispanic mothers only was 8 percent compared to 34 percent for white non-Hispanic mothers.

Other studies have reported elevated risk of smoking for unmarried mothers [27], including those unmarried but cohabiting [28]. Higher prevalence of smoking among unmarried mothers may owe to lower rates of prenatal care in this sub-group [29]. Previous studies also report higher prevalence of smoking during pregnancy for women living with a partner that smokes $[28,30]$. In the present study, women living with a smoker were nearly 6 times as likely to smoke during pregnancy. Elevated risk of smoking among lower income WIC mothers is consistent with other studies [26].

Low-income status of WIC participants in general may also explain the high overall prevalence of smoking in this sample. Smoking prevalence in the current WIC sample was 23 percent, a value higher than a recent national estimate of approximately 11 percent [6]. Although other studies have identified significant effects of age on risk of smoking [7, 9, 20], the present study failed to detect a significant age effect.

Excess pregnancy weight gain was much more common than inadequate weight gain, a trend consistent with other 
Table 2. Prevalence and Risk of Smoking and Inappropriate Pregnancy Weight Gain According to Maternal Characteristics

\begin{tabular}{|c|c|c|c|c|c|c|c|c|c|}
\hline & Smoked & OR & $\mathbf{p}$ & High Weight Gain & OR & $\mathbf{p}$ & Low Weight Gain & OR & $\mathbf{p}$ \\
\hline $\begin{array}{l}\text { Lower income } \\
\text { Higher income }\end{array}$ & $\begin{array}{l}32.5 \% \\
13.5 \%\end{array}$ & 3.09 & $<0.001$ & $\begin{array}{l}45.2 \% \\
42.9 \%\end{array}$ & 1.10 & 0.70 & $\begin{array}{l}24.6 \% \\
20.6 \%\end{array}$ & 1.26 & 0.45 \\
\hline $\begin{array}{l}<12 \text { years education } \\
\geq 12 \text { years education }\end{array}$ & $\begin{array}{l}15.3 \% \\
29.1 \%\end{array}$ & 0.44 & 0.01 & $\begin{array}{l}42.3 \% \\
45.4 \%\end{array}$ & 0.88 & 0.63 & $\begin{array}{l}22.5 \% \\
22.7 \%\end{array}$ & 0.99 & 0.97 \\
\hline $\begin{array}{l}\text { Unmarried / separated } \\
\text { Married }\end{array}$ & $\begin{array}{l}31.3 \% \\
11.4 \%\end{array}$ & 3.53 & $<.001$ & $\begin{array}{l}50.3 \% \\
35.2 \%\end{array}$ & 1.86 & 0.02 & $\begin{array}{l}20.4 \% \\
25.7 \%\end{array}$ & 0.71 & 0.32 \\
\hline $\begin{array}{l}<20 \text { years old } \\
\geq 20 \text { years old }\end{array}$ & $\begin{array}{l}18.9 \% \\
24.1 \%\end{array}$ & 0.73 & 0.42 & $\begin{array}{l}60.4 \% \\
39.7 \%\end{array}$ & 2.32 & 0.01 & $\begin{array}{l}20.8 \% \\
23.1 \%\end{array}$ & 0.87 & 0.72 \\
\hline $\begin{array}{l}\text { Primigravid } \\
\text { Multigravid }\end{array}$ & $\begin{array}{l}18.3 \% \\
24.9 \%\end{array}$ & 0.68 & 0.27 & $\begin{array}{l}60.6 \% \\
37.6 \%\end{array}$ & 2.55 & .001 & $\begin{array}{l}16.9 \% \\
24.9 \%\end{array}$ & 0.62 & 0.18 \\
\hline $\begin{array}{l}\text { Other smoker } \\
\text { No other smoker }\end{array}$ & $\begin{array}{l}45.7 \% \\
12.3 \%\end{array}$ & 6.01 & $<.001$ & $\begin{array}{l}54.3 \% \\
39.2 \%\end{array}$ & 1.85 & 0.02 & $\begin{array}{l}17.3 \% \\
25.1 \%\end{array}$ & 0.62 & 0.17 \\
\hline $\begin{array}{l}\text { Pregnancy weight gain }{ }^{2} \\
\text { Normal (reference) } \\
\text { High weight gain } \\
\text { Low weight gain }\end{array}$ & $\begin{array}{l}16.7 \% \\
28.8 \% \\
21.1 \%\end{array}$ & $\begin{array}{c}-- \\
2.03 \\
1.33\end{array}$ & $\begin{array}{c}-- \\
0.05 \\
0.51\end{array}$ & $\begin{array}{l}-- \\
--\end{array}$ & $\begin{array}{l}-- \\
--\end{array}$ & $\begin{array}{l}-- \\
--\end{array}$ & $\begin{array}{l}-- \\
--\end{array}$ & $\begin{array}{l}-- \\
--\end{array}$ & $\begin{array}{l}-- \\
--\end{array}$ \\
\hline
\end{tabular}

${ }^{\mathrm{I}}$ Odds ratios for each category of BMI, relative to normal BMI group.

${ }^{2}$ Odds ratios for each category of weight gain, relative to normal weight gain group.

Table 3. Adjusted Odds Ratios and 95 Percent Confidence Intervals for Predictors of Smoking and Pregnancy Weight Gain

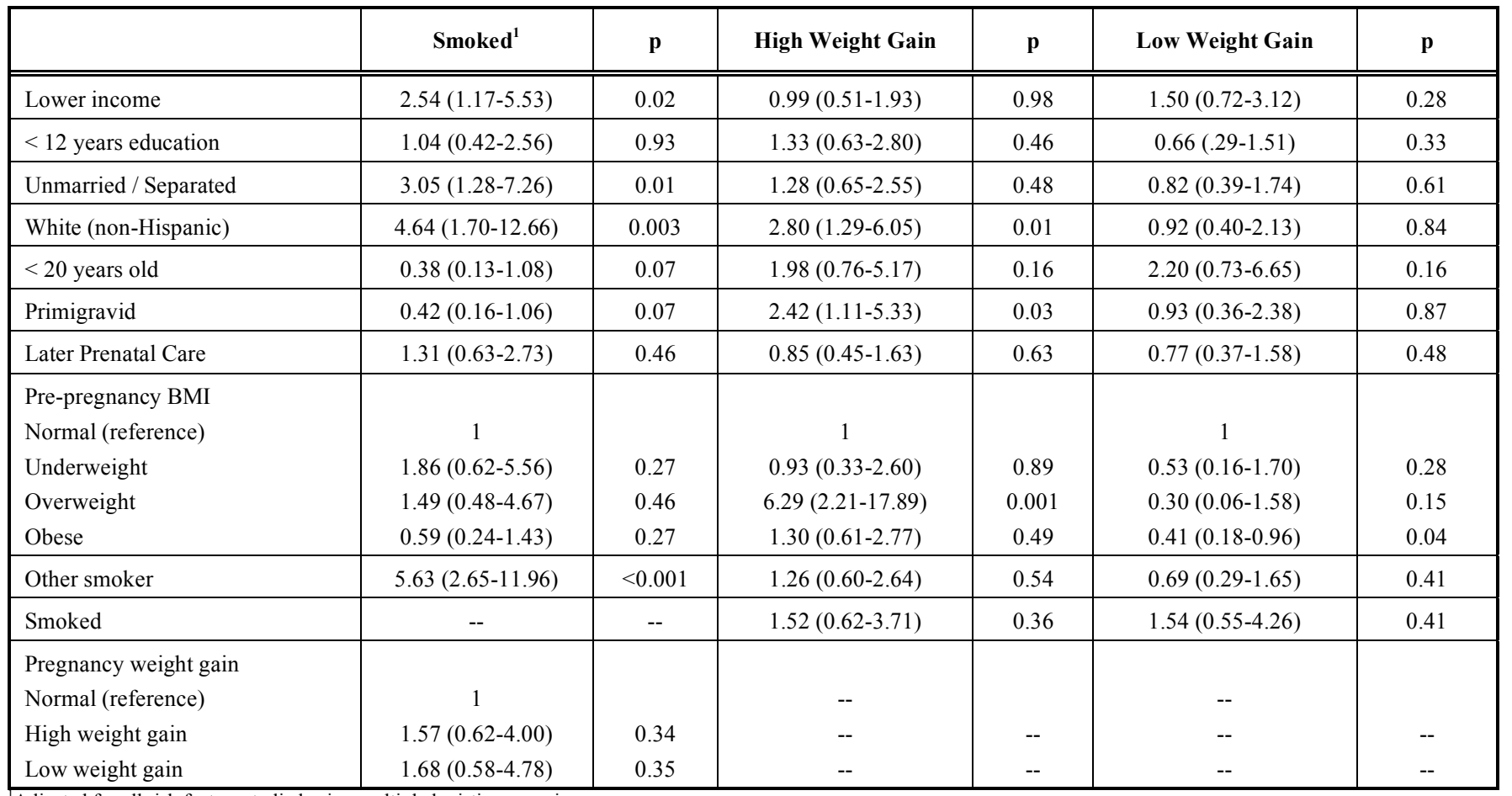

Adjusted for all risk factors studied using multiple logistic regression. 
surveys $[10,31,32]$. There are several potential implications for the high rate of excess weight gain. The combined prevalence of pre-pregnancy overweight and obesity (47 percent) was already high and these women may tend to become even more overweight with successive pregnancies [33]. Maternal obesity and excess weight gain increase the risk of a variety of pregnancy and birth complications $[1,15,34]$.

Unadjusted odds ratios revealed higher risk of excess weight gain among mothers that were unmarried, white (non-Hispanic), under 20 years old, primigravid, and overweight before pregnancy. After adjusting for other risk factors, only race / ethnicity, gravidity, and overweight status significantly predicted excess weight gain. Higher risk of excess weight gain among white non-Hispanic mothers and primigravidas is consistent with previous studies $[10,35]$. Overweight but not obese women in the present study tended to gain excess weight during pregnancy. Other studies suggest that women in this weight category tend to exceed recommended weight gain $[2,35]$. A contributing factor in excess weight gain may be physician advice to gain more weight than recommended during pregnancy [32]. The underlying nutritional factors associated with excess weight gain are undoubtedly complex and may involve interactions with diet, physical activity, and psychosocial stress $[14,36]$.

Demographic and household characteristics were stronger predictors of smoking during pregnancy while biomedical characteristics were stronger predictors of excess pregnancy weight gain. Income, ethnicity, marital status, and presence of another smoker predicted smoking while ethnicity, pregnancy history, and pre-pregnancy weight status significantly predicted excess pregnancy weight gain. A recent study also found identified these biomedical characteristics as predictors of excess weight gain [19]. An interesting result in the present study is that non-white (primarily Hispanic) women faced lower risk for both gestational smoking and excess weight gain. Among Mexican immigrants, the risk of undesirable prenatal behaviors seems to increase with increased acculturation [37,38]. Further study of the acculturation process and associated changes in attitudes and health behaviors is needed to understand these ethnic differences.

There were several limitations of the current study. Sample size did not permit analysis of the large number of possible interactions among predictor variables. However, risk of smoking and excess weight gain was highest among women with multiple identified risk factors. The study relied on reported pre-pregnancy weight and weight gain. Although clinical measurements are desirable, maternal reports of pregnancy variables have been shown to be highly correlated with clinically recorded measures [39]. Finally, certain variables could have been better defined. For example, reporting of marital status made no distinction for cohabiting and reported ethnicity had no provision for degree of acculturation.

\section{CONCLUSION}

This study identified maternal characteristics significantly associated with smoking and excess pregnancy weight gain. Both smoking and inappropriate weight gain impact fetal development by affecting nutrient supply to the fetus [40-42]. Thus, it is critical to identify groups at high risk for these adverse, but modifiable, gestational factors. Importantly, patterns of maternal risk for smoking and excess weight gain were different. Identification of maternal risk profiles is critical for local public health efforts aimed at prevention. Additional research into specific combinations of maternal risk factors that substantially elevate risk is urgently needed to properly focus public health efforts.

\section{ACKNOWLEDGEMENTS}

Sharon Schroeder and the staff at Siouxland WIC provided valuable assistance in data collection.

\section{REFERENCES}

[1] Deruelle P, Houfflin-Debarge V, Vaast P, Delville N, Helou N, Subtil D. Maternal and fetal consequences of increased gestational weight gain in women of normal prepregnant weight. Gynecol Obstet Fertil 2004; 32: 398-403.

[2] Hellerstedt WL, Himes JH, Story M, Alton IR, Edwards LE. The effects of cigarette smoking and gestational weight change on birth outcomes in obese and normal-weight women. Am J Public Health 1997; 87: 591-6.

[3] Secker-Walker RH, Vacek PM. Relationships between cigarette smoking and pregnancy, gestational age, maternal weight gain, and infant birthweight. Addict Behav 2002; 28: 55-66.

[4] Bonellie SR. Effect of maternal age, smoking, and deprivation on birthweight. Paediatr Perinat Epidemiol 2001; 15: 19-26.

[5] Wideroe M, Torstein V, Jacobsen G, Bakketeig LS. Does maternal smoking during pregnancy cause childhood overweight? Paediatr Perinat Epidemiol 2003; 17: 171-9.

[6] Martin JA, Kochanek KD, Strobino DM, Guyer B, MacDorman MF. Annual summary of vital statistics-2003. Pediatrics 2005; 115: 619-34.

[7] Ananthe CV, Kirby RS, Kinzler WL. Divergent trends in maternal cigarette smoking during pregnancy: United States 1990-1999. Paediatr Perinat Epidemiol 2005; 19: 19-26.

[8] Cohen BB, Friedman DJ, Mahan CM, Lederman R, Munoz D. Ethnicity, maternal risk, and birth weight among Hispanics in Massachusetts, 1987-89. Public Health Rep 1993; 108: 363-71.

[9] Phung HN, Bauman AE, Young Y, Tran MH, Hillman KM. Ecological and individual predictors of maternal smoking behavior; Looking beyond individual socioeconomic predictors at the community setting. Addict Behav 2003; 28: 1333-42.

[10] Caulfield LE, Witter FR, Stoltzfus RJ. Determinants of gestational weight gain outside the recommended ranges among black and white women. Obstet Gynecol 1996; 87: 760-6.

[11] Rhodes JR, Schoendorf KC, Parker JD. Maternal influences on child health: preconception, prenatal, and early childhood. Pediatrics 2003; 111: 1181-5.

[12] Abrams B, Selvin S. Maternal weight gain pattern and birth weight. Obstet Gynecol 1995; 86: 163-9.

[13] Bergmann RL, Bergmann KE, Plagemann A, Brauer M, Dudenhausen JW. Pediatr Perinat Epidemiol 2003; 17: 244-9.

[14] Siega-Ritz AM, Kelly RD, Evenson KR, Dole N. Pregnancyrelated weight gain - a link to obesity? Nutr Rev 2004; 62: S10511 .

[15] Sebire NJ, Jolly M, Harris JP, et al. Maternal obesity and pregnancy outcome: a study of 287, 213 pregnancies in London. Int $\mathbf{J}$ Obes 2001; 25: 1175-82.

[16] Kramer MS. Determinants of low birthweight: methodological assessment and meta-analysis. B World Health Organ 1987; 65: 663-737.

[17] Muscati SK, Gray-Donald K, Newson EE. Interaction of smoking and maternal weight status in influencing infant size. Can J Public Health 1994; 85: 407-12.

[18] Thorsdottir I, Bergisdottir BE. Different weight gain in women of normal weight before pregnancy: postpartum weight and birth weight. Obstet Gynecol 1998; 92: 377-83.

[19] Wells CS, Schwalberg R, Noonan G, Gabor V. Factors influencing inadequate and excessive weight gain in pregnancy: Colorado 2000-2002. Matern Child Health J 2006; 10: 55-62.

[20] Stotts AL, Shipley SL, Schmitz JM, Sayre SL, Grabowski J. Tobacco, alcohol, and caffeine use in a low-income, pregnant population. J Obstet Gynecol 2003; 23: 247-51.

[21] Owen AL, Owen GM. Twenty years of WIC: a review of some effects of the program. J Am Diet Assoc 1997; 97: 777-82. 
[22] Iowa Department of Public Health; "Pregnancy Nutrition Surveillance Program; 2005 PNSS County Report" 2005; Available at: $<$ www.idph.state.ia.us/wic/common/pdf/2005_pnss_county.pdf $>$

[23] Institute of Medicine, Subcommittee on Nutritional Status and Weight Gain During Pregnancy. Nutrition during Pregnancy. Washington, D.C. National Academy of Sciences 1990.

[24] May RL. Prepregnancy weight, inappropriate gestational weight gain, and smoking: relationships to birth weight. Hum Biol 2007; 19: 305-10.

[25] Dowling PT, Fisher M. Maternal factors and low birthweight infants: a comparison of blacks with Mexican-Americans. J Fam Pract 1987; 25: 153-8.

[26] Phares TM, Morrow B, Lansky A, et al. Surveillance for disparities in maternal health-related behaviors-selected states, pregnancy risk assessment monitoring system. Surveill Summ 2004; 53: 1-14.

[27] Ventura SJ, Taffel SM. Childbearing characteristics of US - and foreign-born hispanic mothers. Public Health Rep 1985; 100: 64752 .

[28] Penn G, Owen L. Factors associated with continued smoking during pregnancy: analysis of socio-demographic, pregnancy, and smoking-related factors. Drug Alcohol Rev 2002; 21: 17-25.

[29] Balcazar H, Cole G, Hartner J. Mexican-Americans' use of prenatal care and its relationship to maternal risk factors and pregnancy outcome. Am J Prev Med 1992; 8: 1-7.

[30] Kahn RS, Certain L, Whitaker RC. A reexamination of smoking before, during, and after pregnancy. Int J Public Health 2002; 92: 1801-8.

[31] Carmichael S, Abrams B, Selvin S. The pattern of maternal weight gain in women with good pregnancy outcomes. Am J Public Health 1997; 87: 1984-8.

[32] Cogswell ME, Scanlon KS, Beck FS, Schieve LA. Medically advised, mother's personal target, and actual weight gain during pregnancy. Obstet Gynecol 1999; 94: 616-22.

[33] Gunderson EP, Abrams B, Selvin S. The relative importance of gestational gain and maternal characteristics associated with the risk of becoming overweight after pregnancy. Int J Obes 2000; 24: 1660-8.

[34] Jensen DM, Damm P, Sorensen B, et al. Pregnancy outcome and prepregnancy body mass index in 2459 glucose-tolerant Danish women. Am J Obstet Gynecol 2003; 189: 239-43.

[35] Brawarsky P, Stotland NE, Jackson RA, et al. Pre-pregnancy and pregnancy-related factors and the risk of excessive or inadequate gestational weight gain. Int J Gynecol Obstet 2005; 91: 125-31.

[36] Olsen CM, Strawderman MS, Hinton PS, Pearson TA. Gestational weight gain and postpartum behaviors associated with weight change from early pregnancy to $1 \mathrm{y}$ postpartum. Int J Obes 2003 27: 117-27.

[37] Acevedo MC. The role of acculturation in explaining ethnic differences in the prenatal health-risk behaviors, mental health, and parenting beliefs of Mexican-American and European American atrisk women. Child Abuse Negl 2000; 24: 111-27.

[38] Zambrana RE, Scrimshaw SC, Collins N, Dunkel-Shetteret C. Prenatal health behaviors and psychosocial risk factors in pregnant women of Mexican origin: the role of acculturation. Am J Public Health 1997; 87: 1022-6.

[39] Lederman SA, Paxton A. Maternal reporting of prepregnancy weight and birth outcome: consistency and completeness compared with the clinical record. Matern Child Health J 1998; 2: 123-6.

[40] Albuquerque CA, Smith KR, Johnson C, Chao R, Harding R. Influence of maternal tobacco smoking during pregnancy on uterine, umbilical, and fetal cerebral artery blood flows. Early Hum Dev 2004; 80: 31-42.

[41] Jolly MC, Sebire NJ, Harris JP, Regan L, Robinson S. Risk factors for macrosomia and its clinical consequences: a study of 350,31 pregnancies. Eur J Obstet Gynaecol Reprod Biol 2003; 111: 9-14.

[42] Thame M, Osmond C, Bennett F, Wilks R, Forrester T. Fetal growth is directly related to maternal anthropometry and placental volume. Eur J Clin Nutr 2004; 58: 894-900. 